\title{
THE
}

\section{Synthesis of a Fluorescent Conjugated Polymer in the Undergraduate Organic Teaching Laboratory}

Teresa Mako

University of Rhode Island

Mindy Levine

University of Rhode Island, m_levine@uri.edu

Follow this and additional works at: https://digitalcommons.uri.edu/chm_facpubs

The University of Rhode Island Faculty have made this article openly available.

Please let us know how Open Access to this research benefits you.

This is a pre-publication author manuscript of the final, published article.

Terms of Use

This article is made available under the terms and conditions applicable towards Open Access

Policy Articles, as set forth in our Terms of Use.

\section{Citation/Publisher Attribution}

Mako, T., \& Levine, M. (2013). Synthesis of a Fluorescent Conjugated Polymer in the Undergraduate Organic Teaching Laboratory. J. Chem. Educ., 90(10), 1376-1379. doi: 10.1021/ed300824r

Available at: http://dx.doi.org/10.1021/ed300824r 


\section{Synthesis of a fluorescent conjugated polymer in the undergraduate organic teaching}

\section{laboratory}

Teresa Mako and Mindy Levine*

Department of Chemistry, University of Rhode Island, 51 Lower College Road, Kingston, RI 02881

*mlevine@chm.uri.edu

\section{ABSTRACT}

Fluorescent organic polymers are used in a wide range of applications, including explosive sensing, clean energy technologies, and biological detection schemes. However, such polymers are rarely synthesized in an undergraduate organic teaching laboratory, due to their air and moisture sensitivity. The synthesis of a fluorescent organic polymer, poly[2-methoxy-5-(2ethylhexyloxy)-1,4-phenylenevinylene] (MEH-PPV), is described for the upper-division undergraduate organic laboratory. This polymerization is accomplished using straightforward procedures to exclude air and moisture, without requiring the use of a glovebox or strict inertatmosphere conditions. Once synthesized, the polymer is used for two applications, the fabrication of fluorescent thin films and the formation of organic conjugated nanoparticles, and leads to a number of pedagogical opportunities about polymerization, organic fluorescence, solid-state properties, and hydrophobic nanoparticle formation.

\section{KEYWORDS}

upper-division undergraduate; organic chemistry; polymer chemistry; fluorescence spectroscopy; nanotechnology 


\section{Synthesis of a Fluorescent Conjugated Polymer in the Undergraduate Teaching}

\section{Laboratory}

Teresa Mako and Mindy Levine*

Department of Chemistry, University of Rhode Island, 51 Lower College Road, Kingston, RI 02881

*mlevine@chm.uri.edu

\section{BODY TEXT}

Organic fluorescent polymers have been extensively studied in the research laboratory for several years. ${ }^{1}$ These polymers can be viewed as "molecular wires," due to the free exciton migration throughout the conjugated polymer backbone. ${ }^{2,3}$ They have been used for the detection of a number of analytes, including explosives, ${ }^{4,5}$ and biological analytes. ${ }^{6}$ Conjugated polymers have been used in the fabrication of organic light-emitting diodes (OLEDs) ${ }^{7}$ and in the field of organic photovoltaics (OPVs), ${ }^{8}$ and they have been used broadly in the development of clean energy technologies. ${ }^{9}$ Moreover, the doping of conjugated polymers with both metals and nonmetal dopants has led to the development of highly conductive organic polymer-based devices. ${ }^{10}$

Synthesis of conjugated polymers generally proceeds via a metal-catalyzed polymerization reaction. ${ }^{11}$ These reactions require strictly inert atmosphere conditions ${ }^{12}$ to prevent premature termination of the polymer chain. As a result of the strict requirement for inert atmosphere conditions, conjugated polymers have been synthesized only rarely at the undergraduate level. Some isolated examples of conjugated polymer synthesis at the undergraduate level include the synthesis of poly(3-hexylthiophene) via Grignard metathesis polymerization (GRIM) ${ }^{13}$ and the synthesis of polyacetylene via ring-opening metathesis polymerization (ROMP). ${ }^{14}$ 
Reported herein is the synthesis of a conjugated polymer, MEH-PPV (poly[2-methoxy-5(2'-ethylhexyloxy)-p-phenylenevinylene]), in an advanced undergraduate laboratory. ${ }^{15}$ This procedure used Gilch polymerization conditions (mechanism discussed in the Supporting Information), ${ }^{16}$ and required moderate precautions to limit the reaction's exposure to air and moisture. Once the polymer was synthesized, it was utilized for two applications: (a) synthesis of fluorescent organic nanoparticles; ${ }^{17}$ and (b) fabrication of fluorescent thin films. ${ }^{18}$ Nanoparticles of MEH-PPV have been synthesized extensively in the literature, and used for applications including selective drug delivery to knee joints, ${ }^{19}$ detection of hydroxyl radicals, ${ }^{20}$ and intraparticle energy transfer. ${ }^{21}$

Key advantages to the polymer synthesis reported herein include (1) the elimination of the need for a glovebox or glovebag for the polymer synthesis; and (2) the use of the newlysynthesized polymer for multiple applications, which combined to create a truly interdisciplinary laboratory experience.

\section{Pedagogic Value}

Synthesis of fluorescent conjugated polymers provided a myriad of pedagogical opportunities. Although most of the students had learned about polymers in their organic lecture classes, those discussions had not mentioned fluorescent organic polymers. In this experiment, students were introduced to the concepts of polymer synthesis as well as air- and moisturesensitive synthetic procedures. They also learned about organic polymer fluorescence, as well as the mechanism of a Gilch polymerization reaction (discussed in detail in the Supporting Information). Finally, students learned about the hydrophobic effect ${ }^{22}$ in the context of nanoparticle fabrication, ${ }^{23}$ and how the photophysical properties of the polymer changed in the thin films compared to its properties in the organic solvent. 
Skills taught in this experiment (polymerization, thin film fabrication, nanoparticle fabrication) were valuable to organic chemistry students, while engineering and pre-health students also gained exposure to materials science and analytical chemistry techniques. Thus, skills covered in the lab have real-world applicability for students of all interests.

Experimental Organization: Specific goals of this experiment were for students to (1) synthesize a fluorescent organic polymer via a Gilch polymerization reaction; (2) characterize the fluorescent polymer by ${ }^{1} \mathrm{H}$ NMR, UV-Visible, and fluorescence spectroscopy; and (3) utilize the polymer to fabricate fluorescent organic nanoparticles and fluorescent thin films.

This project was performed in three laboratory periods in an upper-division undergraduate organic laboratory course. Students synthesized the polymer in one three-hour session, analyzed its photophysical properties in the second laboratory session, and formed polymer-derived nanoparticles and thin films in the third laboratory period. The experiment reported herein was performed by 14 students.

\section{Experimental Overview (for details, see the Supporting Information)}

\section{Required equipment:}

This experiment required access to ${ }^{1} \mathrm{H}$ NMR, UV-Vis, and fluorescence spectrometers, as well as a spin coater and a sonicator for thin films and particles. This experiment can be run without forming nanoparticles or thin films, and would still provide ample pedagogical opportunities, focused on polymer synthesis and solution-state polymer fluorescence.

\section{Synthesis of MEH-PPV:}




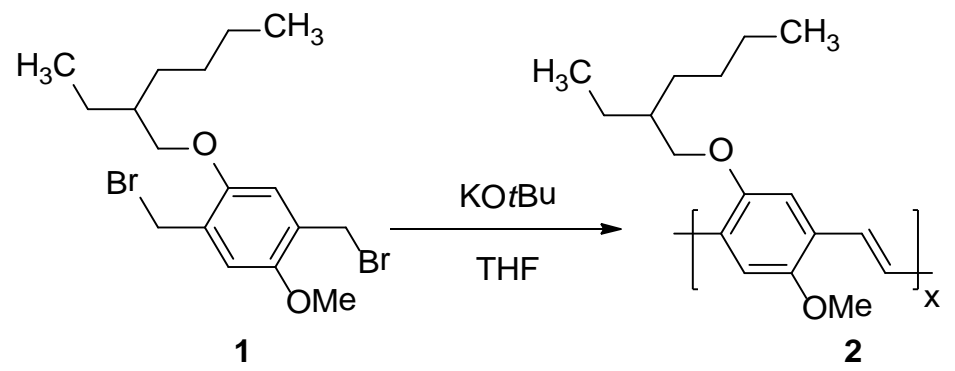

Scheme 1: Synthesis of MEH-PPV 2

2,5-Bis(bromomethyl)-1-methoxy-4-(2-ethylhexyloxy)benzene 1 (1.0 equivalent) was dissolved in oxygen- and moisture-free tetrahydrofuran (THF), and cooled to $0{ }^{\circ} \mathrm{C}$. Potassium tert-butoxide (4.0 equivalents) was dissolved in THF and added via syringe to the solution of $\mathbf{1}$ in THF. After 2 hours of vigorous stirring at $0{ }^{\circ} \mathrm{C}$, the reaction mixture was quenched via the addition of excess methanol, and polymer $\mathbf{2}$ was isolated by vacuum filtration. Yields for this reaction ranged from 32-95\%. The resulting solid was characterized by ${ }^{1} \mathrm{H}$ NMR spectroscopy (in deuterated chloroform), and UV-Visible and fluorescence spectroscopy (as a chloroform solution).

\section{Nanoparticle fabrication: ${ }^{24}$}

A dilute solution of the polymer in THF was added quickly to a flask containing water, while the water was continuously sonicated. THF was removed to yield an aqueous solution of nanoparticles, which was characterized by UV-Visible and fluorescence spectroscopy.

\section{Thin film formation:}

A solution of the polymer in dichloromethane was added to a glass cover slip taped to a microscope slide. The resulting solution was evaporated on a spin processor to yield an orange, fluorescent thin film. The fluorescence of the thin film was measured using a solid-state attachment on a fluorimeter. In the absence of a spin processor, thin films can also be fabricated using a simple cooling fan, following a literature-reported procedure. ${ }^{25}$ 


\section{Hazards}

Potassium tert-butoxide [CAS: 865-47-4] is a flammable solid. 2,5-Bis(bromomethyl)-1methoxy-4-(2-ethylhexyloxy)benzene [CAS: 209625-37-6] is harmful if inhaled or swallowed. Methanol [CAS: 67-56-1] is a highly flammable and toxic liquid and vapor. Tetrahydrofuran [CAS: 109-99-9] is a highly flammable liquid that is harmful if swallowed or inhaled. Acetone [CAS: 67-64-1] is a highly flammable liquid. Dichloromethane [CAS: 75-09-2] is a highly volatile liquid and skin irritant. Chloroform [CAS: 67-66-3] and deuterated chloroform [CAS: 865-49-6] are highly toxic and suspected carcinogens. Appropriate personal protective equipment should be used at all times, and the reagents should only be handled in a wellventilated fume hood. The polymer product, MEH-PPV [CAS: 138184-36-8] may be harmful if inhaled. MSDS sheets are freely available from the vendor at http://www.sigmaaldrich.com.

\section{Results and Discussion:}

In the first step of this experiment, students synthesized the fluorescent conjugated polymer, MEH-PPV, in yields ranging from 32-95\%. A representative student sample was subjected to gel permeation chromatography (GPC) analysis (performed by Dr. Jens Ravnsbæk of MIT), and the results confirmed polymer formation (albeit with a relatively high polydispersity index (PDI)): $\mathrm{M}_{\mathrm{n}}=1.40 \times 10^{5} \mathrm{~g} / \mathrm{mol} ; \mathrm{M}_{\mathrm{w}}=5.69 \times 10^{5} \mathrm{~g} / \mathrm{mol} ; \mathrm{PDI}=4.07$.

Students needed to take reasonable precautions to limit the exposure of their reaction to air and moisture. For most of the students, this synthesis was their first experience conducting air- and moisture-sensitive chemistry, and led to discussions about how to best conduct such reactions, especially in the absence of a glovebox or a Schlenk line. During the two hour reaction, the mixture quickly turned from a colorless solution to a bright orange solution, followed by the formation of a bright red product (upon methanol addition), which was very 
exciting for students to watch. This color change also provided visual confirmation that the polymerization was occurring.

The second step was the characterization of the polymer via spectroscopy. ${ }^{1} \mathrm{H}$ NMR spectra were obtained in deuterated chloroform. Good quality ${ }^{1} \mathrm{H}$ NMR spectra were obtained by most students, and compared to the literature-reported spectra for MEH-PPV. A dilute chloroform solution of the polymer yielded excellent UV-visible and fluorescence spectra (Figure 1). This solution had a $\lambda_{\max }$ absorbance at approximately $500 \mathrm{~nm}$ and a $\lambda_{\max }$ emission at approximately $557 \mathrm{~nm}$.

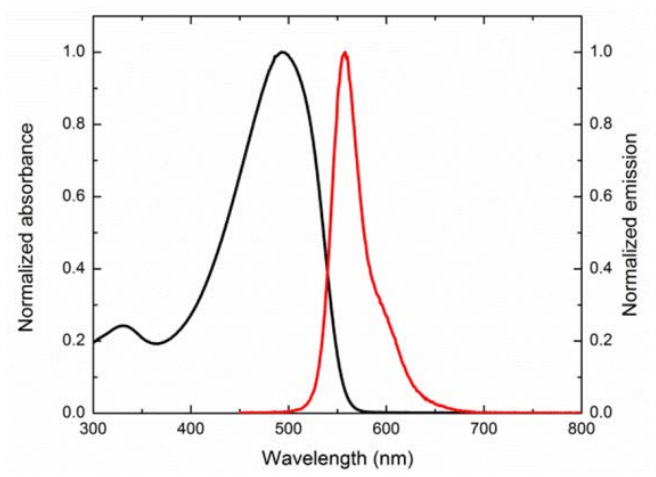

Figure 1: Absorbance and emission of a dilute solution of polymer $\mathbf{2}$ in chloroform

In the third part of this experiment, students fabricated fluorescent nanoparticles and fluorescent thin films, and measured the photophysical properties of the polymer under these conditions. For the nanoparticles, they found that the emission maximum was shifted to $582 \mathrm{~nm}$ (a $25 \mathrm{~nm}$ shift compared to the solution emission maximum), which provided an opportunity to discuss polymer aggregation and bathochromic (red) shifts. Similarly, the thin film fluorescence spectra showed an emission maximum of $577 \mathrm{~nm}$ (a $20 \mathrm{~nm}$ shift compared to the $\lambda_{\max }$ emission of the solution), which again can be attributed to polymer aggregation. Figure 2 highlights the differences in the fluorescence spectra of the polymer under these three conditions, and Figure 3 shows photographs of the polymer in various media. 
Of the 14 students, 13 successfully synthesized the conjugated polymer in the first laboratory period (Goal 1), in yields ranging from 32-95\%. All of the students who synthesized the polymer were able to characterize it using a variety of spectroscopic techniques (Goal 2). The student who was not able to synthesize the polymer was instructed to use another student's polymer for the nanoparticle and thin film formation. Of the 14 students, all of them were able to successfully form fluorescent nanoparticles and fluorescent thin films (Goal 3).

Instructors should be aware of the following problems: (1) Gel formation sometimes occurred during the polymerization reaction. Using a large stirbar and stirring the reaction mixture at a high rate minimized the likelihood of gel formation. If gel formation did occur, students added small amounts of THF as necessary to break up the gel formation. (2) It was somewhat difficult for students to measure a precise mass of the polymer for spectroscopic analyses (i.e. precisely $3 \mathrm{mg}$ ). Students were instructed to add a small amount of polymer to a vial, determine the mass of the polymer, and then calculate how much chloroform to add.

Representative student data can be seen in the accompanying Supporting Information.

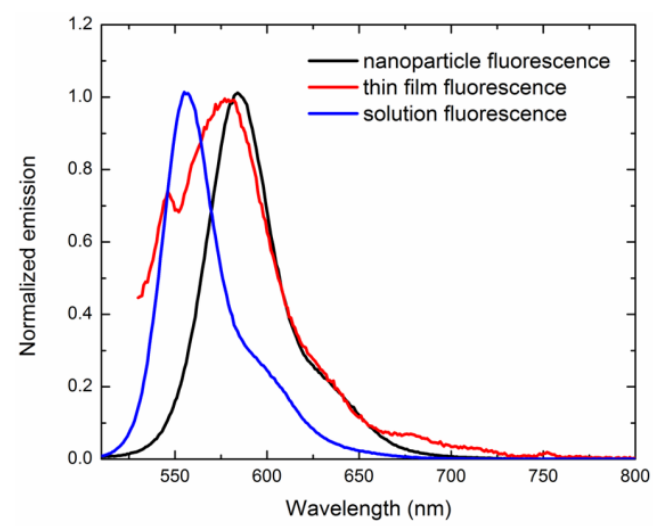

Figure 2: Comparison of the fluorescence of polymer 2 under various conditions 
(a)

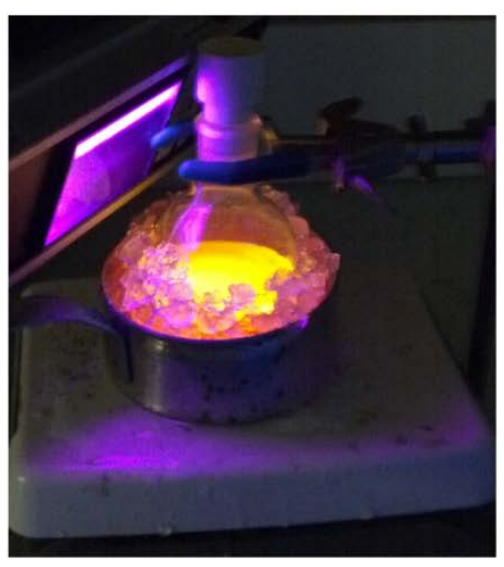

(b)

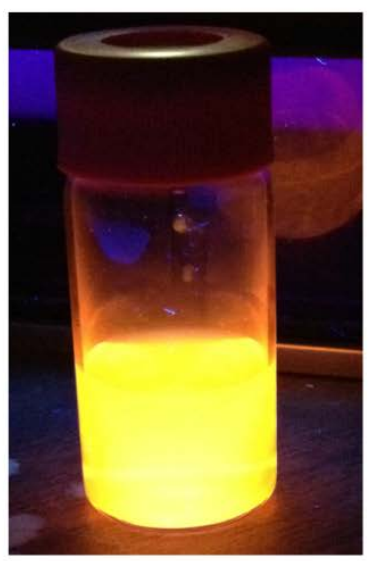

(c)

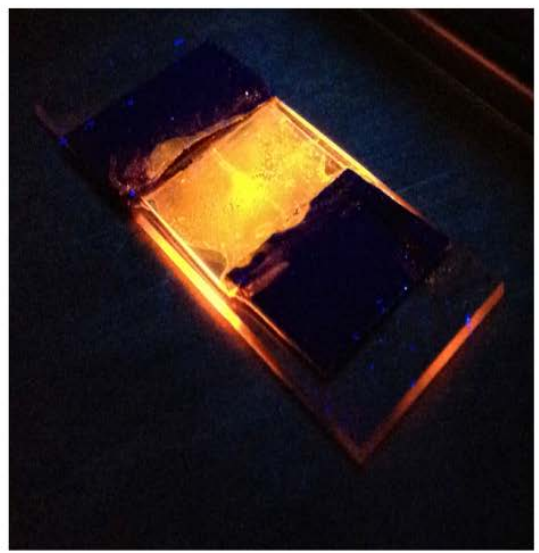

Figure 3: Photos of student-made polymer taken with a hand-held UV-Vis lamp using long wave (365 nm) excitation: (a) in THF solution as the reaction proceeds, (b) as an aqueous nanoparticle solution, and (c) in fluorescent thin films.

\section{Conclusion}

A fluorescent conjugated polymer was synthesized in an upper-division undergraduate teaching laboratory with minimal precautions to minimize air and moisture exposure. The polymerization was robust and high-yielding, and provided students with ample pedagogical opportunities in conjugated polymer chemistry, polymer photophysics, polymeric materials, and nanoparticle chemistry.

\section{Acknowledgements}

Financial support for this project was provided by the University of Rhode Island (URI) Foundation Teaching Grant, as well as by the URI Chemistry Department. Editorial support was provided by Ms. Nicole Serio.

This paper is dedicated to the memory of the late Professor Nicholas Turro, a fantastic educator, scientist, and person.

\section{Supporting Information}


Synthesis details, student handout, notes for instructor, representative student spectra of all synthesized compounds. This material is available via the Internet at http://pubs.acs.org.

\section{Literature Cited}

(1) Thomas, S. W., III; Joly, G. D.; Swager, T. M. Chemical Sensors Based on Amplifying Fluorescent Conjugated Polymers. Chem. Rev. 2007, 107, 1339-1386.

(2) Swager, T. M. The Molecular Wire Approach to Sensory Signal Amplification. Acc. Chem. Res. 1998, 31, 201-207.

(3) Terao, J.; Kimura, K.; Seki, S.; Fujihara, T.; Tsuji, Y. Synthesis of an Insulated Molecular Wire by Click Polymerization. Chem. Commun. 2012, 48, 1577-1579.

(4) Yang, J.-S.; Swager, T. M. Porous Shape Persistent Fluorescent Polymer Films: An Approach to TNT Sensory Materials. J. Am. Chem. Soc. 1998, 120, 5321-5322.

(5) Zhang, L.-H.; Jian, T.; Wu, L.-B.; Wan, J.-H.; Chen, C.-H.; Pei, Y.-B.; Lu, H.; Deng, Y.; Bian, G.-F.; Qiu, H.-Yu; Lai, G.-Q. 2,3,4,5-Tetraphenylsilole-Based Conjugated Polymers: Synthesis, Optical Properties, and as Sensors for Explosive Compounds. Chem. Asian J. 2012, 7, 1583-1593.

(6) Wang, Y.; Pu, K.-Y.; Liu, B. Anionic Conjugated Polymer with Aptamer-Functionalized Silica Nanoparticle for Label-Free Naked-Eye Detection of Lysozyme in Protein Mixtures. Langmuir 2010, 26, 10025-10030.

(7) Al Salhi, M. S.; Alam, J.; Dass, L. A.; Raja, M. Recent Advances in Conjugated Polymers for Light Emitting Devices. Int. J. Molec. Sci. 2011, 12, 2036-2054.

(8) Facchetti, A. $\pi$-Conjugated Polymers for Organic Electronics and Photovoltaic Cell Applications. Chem. Mater. 2011, 23, 733-758. 
(9) Halim, M. A. Harnessing Sun's Energy with Quantum Dots Based Next Generation Solar Cell. Nanomaterials 2013, 3, 22-47.

(10) Heeger, A. J. Semiconducting and Metallic Polymers: the Fourth Generation of Polymeric Materials. Chinese J. Polym. Sci. 2001, 19, 545-572.

(11) Sakamoto, J.; Rehahn, M.; Wegner, G.; Schlueter, A. D. Suzuki Polycondensation: Polyarylenes a la Carte. Macromol. Rapid Commun. 2009, 30, 653-687.

(12) Lam, J. W. Y.; Tang, B. Z. Functional Polyacetylenes. Acc. Chem. Res. 2005, 38, 745-754.

(13) Pappenfus, T. M.; Hermanson, D. L.; Kohl, S. G.; Melby, J. H.; Thoma, L. M.; Carpenter, N. E.; da Silva Filho, D. A.; Bredas, J.-L. Regiochemistry of Poly(3-hexylthiophene): Synthesis and Investigation of a Conducting Polymer. J. Chem. Educ. 2010, 87, 522-525.

(14) Moorhead, E. J.; Wenzel, A. G. Two Undergraduate Experiments in Organic Polymers: The Preparation of Polyacetylene and Telechelic Polyacetylene via Ring-Opening Metathesis Polymerization. J. Chem. Educ. 2009, 86, 973-975.

(15) Lin, K.-F.; Fan, Y.-L.; Chow, H.-L. Origin of the Methylene Bonds in Poly[2-methoxy-5(2'-ethyl-hexyloxy)-1,4-phenylenevinylene] Prepared According to Gilch's Method: Novel Applications. Polym. Int. 2006, 55, 938-944.

(16) Wiesecke, J.; Rehahn, M. Direct Observation of $\alpha$-Chloro-p-quinodimethane as the Real Monomer in the Gilch Polymerization Leading to Poly(p-phenylene vinylene)s. Macromol. Rapid Commun. 2007, 28, 188-193.

(17) Tian, Z.; Yu, J.; Wu, C.; Szymanski, C.; McNeill, J. Amplified Energy Transfer in Conjugated Polymer Nanoparticle Tags and Sensors. Nanoscale 2010, 2, 1999-2011. 
(18) Salleo, A.; Kline, R. J.; DeLongchamp, D. M.; Chabinyc, M. L. Microstructural Characterization and Charge Transport in Thin Films of Conjugated Polymers. Adv. Mater. 2010, 22, 3812-3838.

(19) Morgen, M.; Tung, D.; Boras, B.; Miller, W.; Malfait, A.-M.; Tortorella, M. Nanoparticles for Improved Local Retention after Intra-Articular Injection into the Knee Joint. Pharma. Res. 2013, 30, 257-268.

(20) Wang, J.; Xu, X.; Zhao, Y.; Zheng, C.; Li, L. Exploring the Application of Conjugated Polymer Nanoparticles in Chemical Sensing: Detection of Free Radicals by a Synergy Between Fluorescent Nanoparticles of Two Conjugated Polymers. J. Mater. Chem. 2011, 21, 1869618703.

(21) Wu, C.; Peng, H.; Jiang, Y.; McNeill, J. Energy Transfer Mediated Fluorescence from Blended Conjugated Polymer Nanoparticles. J. Phys. Chem. B 2006, 110, 14148-14154.

(22) Lazaridis, T. Solvent Size vs Cohesive Energy as the Origin of Hydrophobicity. Acc. Chem. Res. 2001, 34, 931-937.

(23) Yang, S.; Pelton, R. Nanoparticle Flotation Collectors II: The Role of Nanoparticle Hydrophobicity. Langmuir 2011, 27, 11409-11415.

(24) Szymanski, C.; Wu, C.; Hooper, J.; Salazar, M. A.; Perdomo, A.; Dukes, A.; McNeill, J. Single Molecule Nanoparticles of the Conjugated Polymer MEH-PPV, Preparation and Characterization by Near-Field Scanning Optical Microscopy. J. Phys. Chem. B 2005, 109, 8543-8546.

(25) Chakraborty, M.; Chowdhury, D.; Chattopadhyay, A. Spin-Coating of Polystyrene Thin Films as an Advanced Undergraduate Experiment. J. Chem. Educ. 2003, 80, 806-809. 